\title{
Validation of landslide hazard assessment by means of GPS monitoring technique - a case study in the Dolomites (Eastern Alps, Italy)
}

\author{
F. Tagliavini ${ }^{1}$, M. Mantovani ${ }^{1}$, G. Marcato ${ }^{1}$, A. Pasuto ${ }^{1}$, and S. Silvano ${ }^{1}$ \\ ${ }^{1}$ CNR-IRPI - National Research Council of Italy, Research Institute for Hydrological and Geological Hazard Prevention, \\ C.so Stati Uniti 4, 35127 Padova, Italy
}

Received: 24 October 2006 - Revised: 20 February 2007 - Accepted: 20 February 2007 - Published: 26 February 2007

\begin{abstract}
In the last years a research project aimed at the assessment of the landslide hazard and susceptibility in the high Cordevole river basin (Eastern Dolomites, Italy) have been carried out. The hazard map was made adopting the Swiss Confederation semi-deterministic approach that takes into account parameters such as velocity, geometry and frequency of landslides. Usually these parameters are collected by means of geological and morphological surveys, historical archive researches, aerophotogrammetric analysis etc. In this framework however the dynamics of an instable slope can be difficult to determine. This work aims at illustrating some progress in landslide hazard assessment using a modified version of the Swiss Confederation semi-deterministic approach in which the values of some parameters have been refined in order to accomplish more reliable results in hazard assessment. A validation of the accuracy of these new values, using GPS and inclinometric measurements, has been carried out on a test site located inside the high Cordevole river basin.
\end{abstract}

\section{Introduction}

In the 20th century numerous hydrological and geological disarray events caused the loss of at least 5381 lives in Italy and left over 100000 people homeless or evacuated (Guzzetti, 2000). In the past 50 years, direct damage to assets and properties was estimated around 500 million euros per year (Catenacci, 1992). Following these disastrous events, there has been growing interest nationally and internationally in the search for new strategies aiming at mitigating geological and hydrological risks.

In addition there is growing awareness from both public administrations and the general public that a correct policy of

Correspondence to: F. Tagliavini

(fabrizio.tagliavini@irpi.cnr.it) territorial management can be attained only through in-depth understanding of natural processes. This interest led to the acquisition of a greater knowledge of landslide mechanisms and the definition of the useful instruments to manage and forecast landslides evolution.

After the Sarno (Campania Region) and Soverato (Calabria Region) mudflow disasters, which claimed several lives in 1998 and 2000 respectively (Zanchetta et al., 2004), a specific law (267/98) was passed with the goal of locating and zoning the areas prone to hydrological and geological risk. Numerous methodologies have been tested to obtain an evaluation of the risk situation of the territory as objective as possible. This work aims at illustrating some progress in landslide hazard assessment using a modified version of the Swiss Confederation semi-deterministic approach (Heiniman et al., 1998) in which the values of some parameters have been refined in order to accomplish more reliable results in hazard assessment. A validation of the accuracy of these new values, using GPS and inclinometric measurements, has been carried out on a test site located inside the high Cordevole river basin, showing interesting results for territorial planning and management.

\section{Present soil conservation law in Italy}

A lack of prevention means and control over the territory by the authorities can be considered as a main factor contributing to the high social costs of landslide events. A modern developed country should have a set of rules for defining standards both for strict soil conservation policy and for safeguarding the public against natural hazards. In Italy where $38 \%$ of the national territory are hilly and $39 \%$ are mountainous, the implementation of such norms is an absolute necessity if the loss of human lives and economic assets caused by landslides and floods is to be reduced. In recent decades existing norms have been continuously updated and improved,

Published by Copernicus GmbH on behalf of the European Geosciences Union. 
Table 1. Territory class risk according to law no. $267 / 98$.

\begin{tabular}{lll}
\hline Class & Risk Level & Description \\
\hline R4 & Very High & $\begin{array}{l}\text { Possibility of loss of human lives and serious health consequences for } \\
\text { the population; severe damage of the buildings, infrastructures and } \\
\text { environment; destruction of socio-economic activities. }\end{array}$ \\
R3 & High & $\begin{array}{l}\text { Possible problems for the safety of the population, functional dam- } \\
\text { ages to buildings and infrastructures, which became unfit for use, dis- } \\
\text { ruption of socio-economic activities and considerable damage to the } \\
\text { environment. } \\
\text { Minor damage to buildings, infrastructures and environmental her- } \\
\text { itage, without compromising the safety of the population or the fitness } \\
\text { of buildings, infrastructures and socio-economic activities. } \\
\text { Marginal damage to socioeconomic activities and to the environment. }\end{array}$ \\
R1 & Low &
\end{tabular}

even if this has always taken place following the emotional reaction to major catastrophes. The main Italian law dealing with environmental management is law no. 267/98, which was passed after the disastrous Sarno events that claimed over 150 lives. The law defines territorial control and management pattern in order to assess and zone hydrogeological risk. For the first time this law pinpoints, as its primary goals, the prevention and forecast of hydrogeological catastrophes. In addition, a series of short and long-term planning interventions have been set up, one of which is a special plan for the most urgent measures concerning maximum hazard areas, together with a more comprehensive plan (plan for hydrogeological adjustment - PAI) which provides for the identification and analysis of all areas at risk all over Italy.

The risk zonation is made by attributing one of the four risk levels defined by law no. 267/98 (Table 1). The law provides suitable guidelines not only for existing settlements and infrastructures but also for urban and territorial planning, so as not to trigger off new risk situations due to improper use of the territory. Furthermore the law clearly defines the restrictions in the use of the high risk areas.

\section{Methodological approach}

Considerable difficulties have emerged in the application of the rules introduced by law no. 267/98 because it establishes that the "risk" must be calculated directly on the basis of foreseen or foreseeable damage. It does not, however, provide informations on how to quantify the characteristics of disarray processes and their possible evolution. For this reason, territorial management boards have decided to follow alternative paths taking into account the characteristics and distribution of landslides and risk elements, which give priority to the definition of hazard rather than risk.

As a consequence, in north-eastern Italy the Swiss Confederation semi-deterministic approach developed by Heinimann et al. (1998) was adopted. This method allows greater objectivity in the definition of the parameters involved in haz- ard assessment by using matrices compiled on the basis of the combination of probability of occurance (frequency) and magnitude of the phenomena, followiong Fell (1994), Canuti and Casagli (1996) and Crescenti (1998).

Particular attention was given to the analysis of procedures in vulnerability assessment. In the most frequently used methods, the degree of expected loss is usually expressed by a value ranging between 0 (no loss) and 1 (total loss). Nevertheless, in contrast with other natural processes, such as flooding and earthquakes, it is very difficult to assess vulnerability resulting from landslides, at basin-scale or region-scale studies. This is due to the complexity and wide range of landslide processes and, therefore, to the typology of structures affected. In addition, the assessment of risk and of economic losses caused by a certain disarray event should not take into account only the value of the elements involved (direct damage), but also consider the dynamic of economic processes which are typical of the investigated area, in other words, what economists define as "indirect damage". Therefore not only the possible structural damage to assets subject to risk (e.g., transport infrastructure, power lines, tourism, handicraft activities and industrial structures) should be assessed but also indirect economic losses resulting from the disruption of these assets and from the suspension of and/or administrative activities activities.

The need to operate at a regional scale, as in this case study, has suggested to adopt a simplified methodology to render results and risk elements homogeneous by defining, for each landslide, only the hazard. The determination of vulnerability and risk has been deliberately neglected since it could not be proposed in this case due to lack of economic expertises.

The essential steps of the methodology adopted are:

- identification of landslide processes (landslides map);

- assessment of the intensity or magnitude of disarray processes;

- assessment of hazard; 


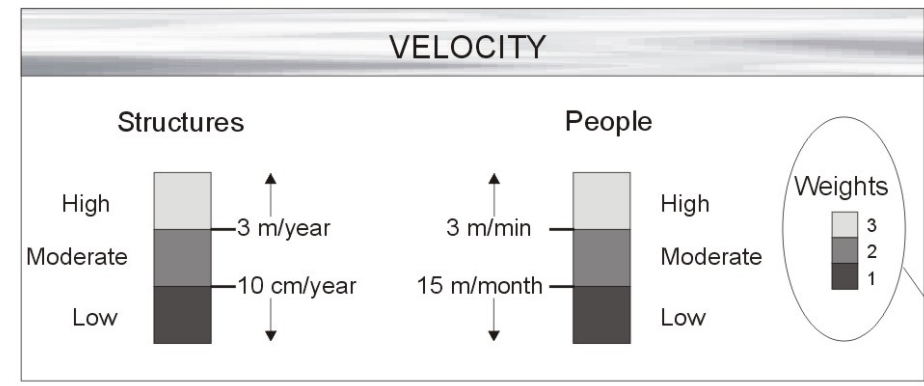

\section{MAGNITUDE}

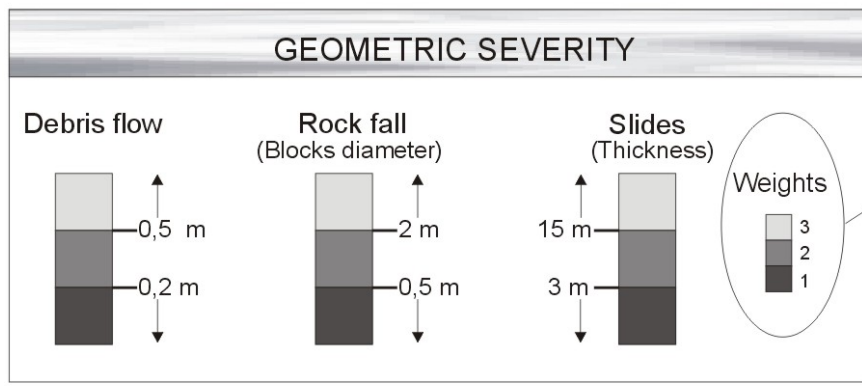

Values

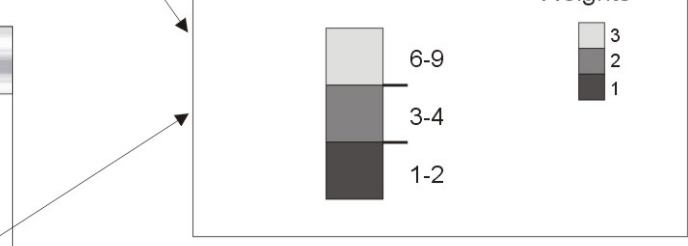

Weights

$6-9$

Fig. 1. Matrices for the velocity and geometric severity classification, the product of the two weights gives the magnitude value.

The intensity or magnitude should produce information on the energy accumulated by each landslide process during its movement.

The basic and fundamental element for landslide hazard assessment should be a landslide inventory map containing the following elements:

- landslides typology (according to Varnes, 1984);

- affected or prone areas;

- state of activity;

- geometric parameters;

- possible evolution of the phenomenon.

In the past years the methodology suggested by Heinimann et al. (1998) has been often applied to the north eastern Italian basins (Pasuto et al., 2004). These experiences pointed out various problems concerning reliability of the data collected in comparison to the requested parameters. In fact if, on one hand it is correct to separate the velocity and the volume in the landslide magnitude evolution, on the other hand it is not possible to provide monitoring systems that could realistically discriminate landslide velocity working on a basin scale, as indicated by the Swiss Confederation semideterministic approach. In the high Cordevole river basin, for example, more than 800 landslides were mapped. This number makes obviously unfeasible any kind of monitoring system to be established. Therefore the only way to obtain
Table 2. Landslide frequency intervals proposed by Heinimann et al. (1998).

\begin{tabular}{cl}
\hline Return Time & Landslide Activity \\
\hline$<1$ year & active, continuous and/or intermittent landslides \\
1-30 years & dormant - high-frequency episodic landslides \\
30-100 years & dormant - mid-frequency episodic landslides \\
$100-1000$ years & dormant - low-frequency episodic landslides \\
$>1000$ years & non-active or very-low-frequency landslides \\
\hline
\end{tabular}

reliable results was to collect data on the basis of morphological evidences, multi-temporal aerophotographs and historical data. In order to get over these limitations, new matrices with different ranges both of velocity and geometric severity were defined by the authors.

The different velocity intervals, schematically illustrated in Fig. 1, take into account the definitions already proposed in the literature, which define the velocity of $3 \mathrm{~m} / \mathrm{min}$ as the maximum value for alerting people and evacuating buildings.

The combination of rating values, intended as the product of the velocity and the geometric severity, deduced from figure and calculated for each identified landslides, allows to calculate a new matrix whose values define the magnitude of the process. 
HAZARD

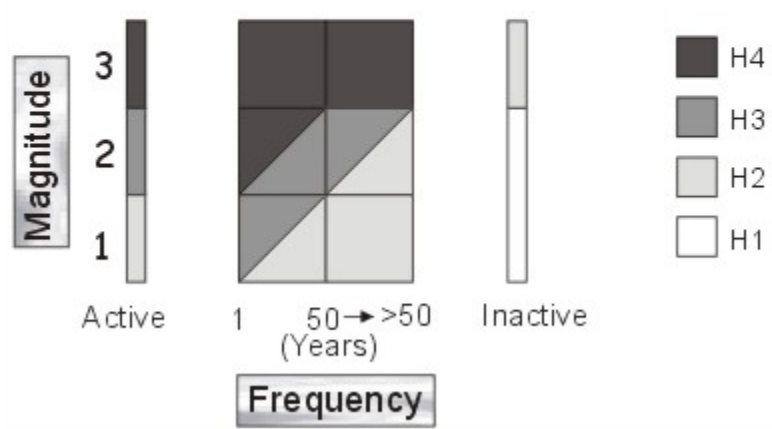

Fig. 2. Interaction matrix used for assessing landslide hazard.

Hazard is defined as the probability that a given event of a given magnitude may occur in a given time interval (Varnes, 1984). After the magnitude of a landslide has been evaluated, in order to asses the hazard it is necessary to define a frequency of the phenomena. Nevertheless, the determination of time occurrence may present considerable difficulties. Data on the recurrence of landslide events are usually scarce or non-existent. Only occasionally and with reference to processes such as debris flows and soil slips, that are directly linked to particular pluviometric events, field investigations are carried out. Existing databases and historical bibliographic references allow an assessment of temporal distribution. More frequently, owing to the low number of studied events and the lack of adequate historical series, the time occurrence cannot be defined with sufficient reliability.

Considering the lack of historical data for statistically defining the frequency, Heinimann et al. (1998) suggest to split the time scale into five temporal classes. These classes were statistically defined on the basis of data on the recurrence of different landslide types, and calibrated using geomorphological evidences, analyses from archives of historical photos and aerial imagery. The five temporal classes are so defined by Heinimann et al. (1998) in Table 2.

Nevertheless this subdivision appears too generic since it does not take into account the peculiarities of the investigated areas or the different distribution and amount of historical information available. For these reasons the classes have been redesigned according to the characteristics of the study areas as follows:

- Active landslides (continuous);

- Non-active landslides;

- Dormant landslides with return time lower than 50 years;
- Dormant landslides with return time higher than 50 years.

This temporal subdivision is justified by two factors. On the one hand, the need to establish time limitation, trying to simplify as far as possible the methodological approach; on the other hand, the awareness that, in the safeguarding of public safety, there are no substantial differences, in terms of hazard, if return times of a few years or decades are considered. In fact, it is quite probable that major damage may occur just in the second case, since disarray processes which have been dormant for a long time might induce false perceptions of risk conditions among the population and lead to the use of areas which should instead remain unspoiled because of their precarious stability conditions.

In particular, as regards north-eastern Italy, it seems acceptable temporal limits between 50 and 100 years. The class up to 50 years would include also the disarray processes occurring in concomitance with the disastrous flood of 1966 (Castiglioni, 1973; Croce et al., 1973), which struck also Florence, Venice and North Eastern Italy, and which can be considered as the boundary for the diffusion and intensity of disarray processes that may occur during particularly exceptional meteorological events. In addition, the first complete aerial survey, which is a fundamental tool for assessing the evolution of a given territory, goes back to 1954. The methodological scheme utilised allows to define a basis matrix, according to which, one of the four hazard classes listed in Fig. 2 will be assigned to each landslide process examined.

The four hazard classes obtained might now have a sort of correspondence with the four risk classes identified by Law no. 267/98, since the possibility of damage to assets and people can be associated to each of the hazard classes, although the difference has to be clear.

Once elaborated the new matrices the need was to validate the new values according to the real movements of the landslide. To accomplish this aim, a monitoring system constituted by GPS network and an inclinometric tube was installed on a sub-basin of the study area.

\section{Case study}

The illustrated methodological approach has been tested in the Cordevole river basin, in the province of Belluno (northeastern Italy). The area, that stretches over some $50 \mathrm{~km}^{2}$, is completely located within the Dolomite Region with a difference in altitude from $1200 \mathrm{~m}$ a.s.l. to $3100 \mathrm{~m}$ a.s.l. (Fig. 3).

The basin is characterised by steep slopes made up of limestone, dolomite and also of some consistent volcanic sandstone. Instead the low slope angles present in the area are due to flyshoid bedrock, morainic deposits and product of their weathering.

Rocks cropping out in the area stretch in age from late Permian to Norian (Bosellini, 1996), with their uppermost parts constituted by dolomitic rocks forming isolated peaks 


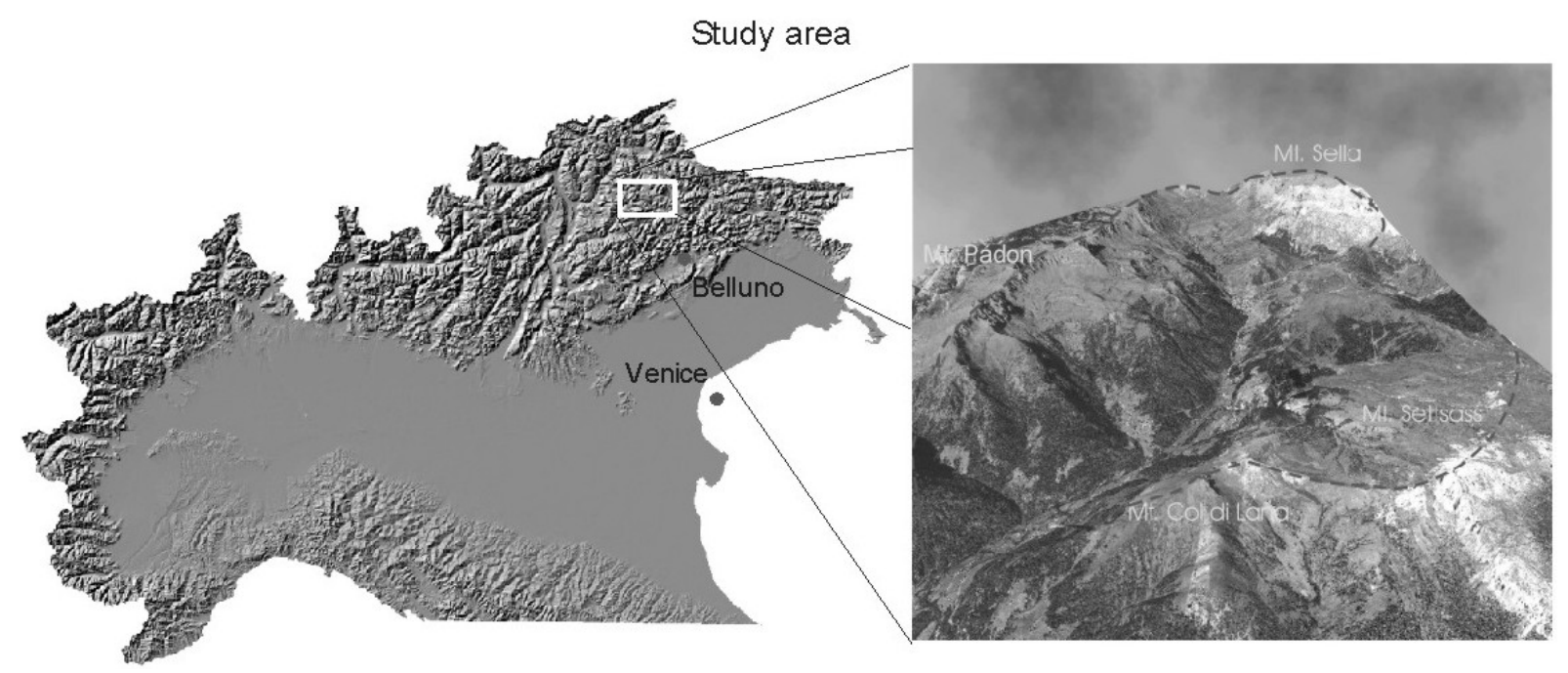

Fig. 3. Location of the study area.

or high standing plateaus. At the reef margins, they are interlaced with basin deposits of volcanic, carbonaceous or calcareous origin, often deposited as turbidites, that can now be found on slopes underlying the Dolomite mountains. They are mainly constituted by weak-layered rocks, with marl or limestone strata up to $50 \mathrm{~cm}$ thick, alternating with thin clay shale and claystone strata forming packs up to $1 \mathrm{~m}$ thick.

The area is affected by important tectonic structures, prevalently related to the Tertiary NE-SW trending Alpine compression (Doglioni and Bosellini, 1987). In the study area faults have been classified by geometric and kinematic elements, able to discriminate among low angle faults, thrust faults, tension faults, normal faults and thrusts. Moreover, folds of regional and/or local extension have been mapped too.

In the study area, precipitations are mainly concentrated during summer and autumn seasons, with an annual mean of about $920 \mathrm{~mm}$.

Particularly prominent are landforms and deposits due to gravitational mass movements. Landslide deposits vary from rock falls to debris flows in the dolomitic cliffs and from rotational slides to earth flows in slopes made up of pelitic rock types.

All data useful for the analysis have been derived from field activities, photo interpretations and existing databases. The landslide inventory map and the predictor patterns supporting information on landslide conditioning factors, have been collected, critically reviewed, digitised and implemented into the project database, managed within a geographical information system (GIS).

The following maps have been initially used:

- landslide inventory map, consisting of about 800 polygons. The map is linked to attribute tables, contain- ing information on type, style of activities, geometrical characteristics, etc.

- bedrock map, depicting the main geological units outcropping in the area;

- morpho-structural map, representing detailed morphostructural elements;

- distance from tectonic lines, buffering the main tectonic discontinuities;

- land use map, indicating the main land use units that might affect the hydrological condition and soil strength;

- distance from rivers, buffering the streams of different orders;

- slope geometry, such as altitude, slope angle, aspect, longitudinal and transverse slope curvature. Morphometric and hydrological parameters have been automatically extracted from a digital elevation model, through neighbourhood operations (in part available beforehand, in part specifically designed within the GIS). Additional parameters such as watershed area, drainage density, drainage network order, channel length, etc. have been derived and used.

For analysis purposes, all thematic maps at 1:5000 scale have been transformed into a raster format with a pixel size of $5 \times 5 \mathrm{~m}$.

The geological and morphological survey of the territory allowed us to identify that more than $20 \%$ of the area are affected by landslides and that most of them belong to the two main typologies: earth flow and debris flow (Fig. 4). 


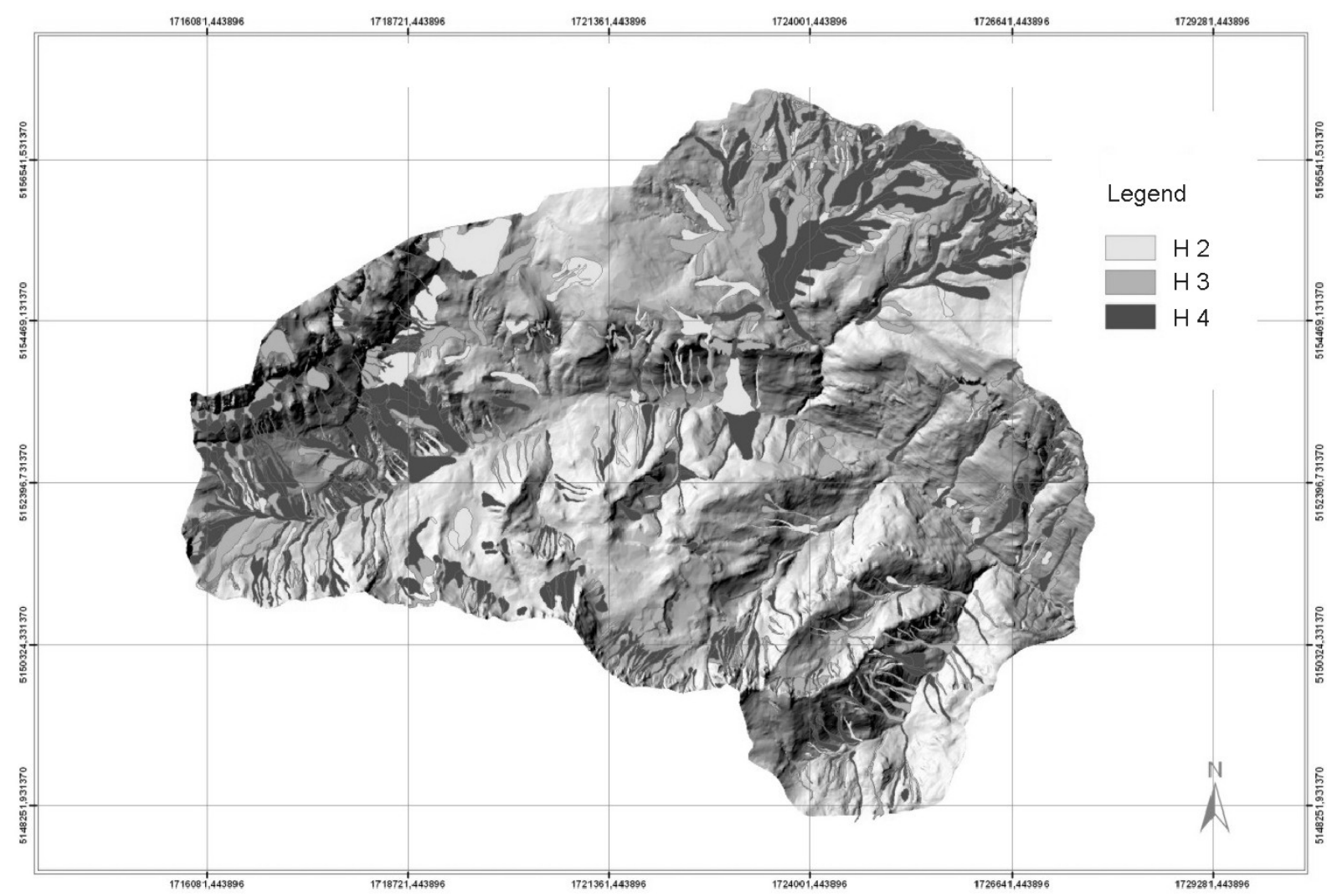

Fig. 4. Cordevole upper basin Hazard map.

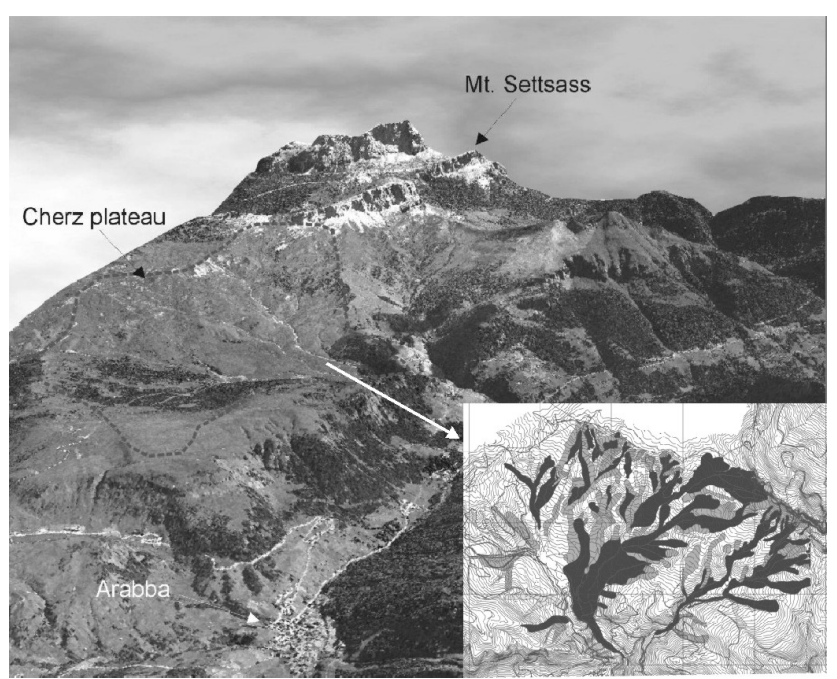

Fig. 5. Cherz plateau and its hazard classification.

In this framework the Cherz plateau was identified as area of particular interest due to the high concentration of landslides (almost 200), with wide range of velocity and geometric severity (Fig. 5). The Cherz plateau lithology consists of an alternance of marls and sandstones; this type of lithology, along with the high amount of rainfall, causes a large number of landslides distinguished by rotational slides and earth flow. Therefore this area has been selected in order to test the above illustrated hazard assessmentmethod and verify its reliability by means of detailed investigations and monitoring.

Further to geomorphological surveys and aerial photo interpretation the hazard was classified according to the new matrices proposed in this paper (Fig. 5).

Once assessed the hazard according to the new matrices the new goal was to validate the results. To do that a GPS network consisting of 30 benchmarks and an inclinometric tube were installed (Fig. 6).

\section{Monitoring system}

The GPS control network was realized in order to monitor the rate of superficial deformation caused by the landslide to better define the hazard matrix. The GPS monitoring system consists of 1 reference benchmark located in a stable area and of 30 benchmarks spread all over the unstable slope. The length of the baselines ranges between $2976 \mathrm{~m}$ and $137 \mathrm{~m}$. In order to warrant the repetitiveness of the surveys, avoiding positioning errors, a forced centring system was realized for each benchmark. During the GPS surveys 4 geodetic (dual frequency) receivers were employed. Static relative 


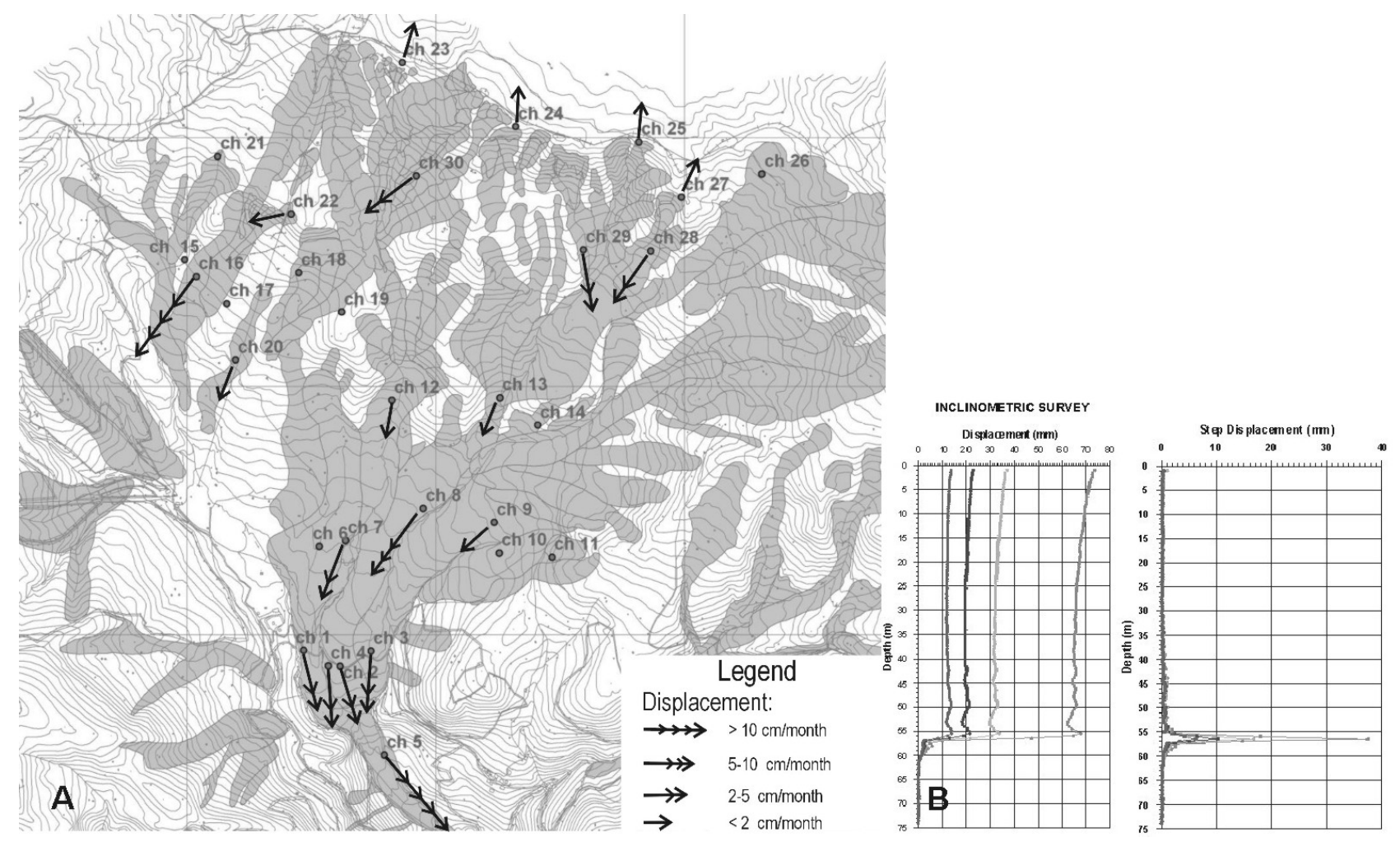

Fig. 6. (a) planar displacement, as oserved from GPS survey, (b) displacement of the slip surface, data from inclinometric tube.

positioning technique was used in order to achieve more accurate results (Hofmann-Wellenhof et al., 2001), within a site occupation time of $20 \mathrm{~min}$, a 2 second sampling rate and a $15^{\circ}$ cut off angle. Tropospheric effects were calculated using Hopfield model. Starting from November 2004, 4 GPS surveys were carried out during two and a half years investigation period. The stability of the reference station, that was materialized over consistent bedrock, was checked during every survey using the permanent station located in Bolzano (Itay) at about $44 \mathrm{~km}$ far from the site. The survey parameters such as the number of reference points and the site occupation time were chosen after a network design simulation according to the maximum accuracy achievable and the instrumentation available. The results are summarized in Tables 3 and 4 .

The displacements recorded by 9 benchmarks (ch06, ch10, ch11, ch14, ch15, ch17, ch18, ch19, ch21, ch26) are smaller then the relative error ellipses so they are not significant and the points can be considered stable so far. Benchmarks ch01, ch02, ch03, ch04, ch07 show a quasi-constant rate of displacement with an average ranging from 3 to $4.4 \mathrm{~cm} /$ month and a slight increase of the velocity. A significant acceleration between July 2005 and October 2005 has been recorded by benchmarks ch08, ch16, ch28, ch29, ch30 although for the last 3 points the rate of displacements average between 1.1 and $2.1 \mathrm{~cm} /$ month while for ch08 exceed $6 \mathrm{~cm} /$ month and almost reaches $13 \mathrm{~cm} /$ month for ch16. Slower displacements ranging between 1 and $0.3 \mathrm{~cm} /$ month have been recorded by benchmarks ch09, ch12, ch13, ch20, ch22. Regressive displacements that are in good agreement with the dynamical evolution of the crown of the landslide are witnessed by backward displacements collected by benchmarks ch23, ch 24 , ch 25 , ch27. Finally point ch05, located at the toe of the landslide, recorded an average rate of movement of $15.9 \mathrm{~cm} /$ months with a continuous increment of speed that reached $17.6 \mathrm{~cm} /$ month.

The inclinometric tube was installed on November 2004 in order to evaluate both the rate of deep displacements caused by the landslide and the position of its sliding surface. Four surveys were carried out before the tube breaking on January 2005. The data so far collected showed the presence of the main sliding surface at a depth of $55 \mathrm{~m}$ with a constant rate of the deformation of about $4.75 \mathrm{~mm} / \mathrm{month}$. This result agrees almost perfectly with the rate of constant deformation recorded by benchmark ch $4(3.8 \mathrm{~cm} / \mathrm{month})$ that is the closest to the inclinometric tube.

\section{Conclusions and discussion}

The monitoring system was used to validate the new parameters adopted for the Swiss Confederation semi-deterministic approach. The GPS monitoring technique allows us to 
Table 3. Cumulative planar displacements, minus sign shows regressive displacements.

\begin{tabular}{cccc}
\hline \multicolumn{4}{c}{ Cumulative Planar Displacements [cm] } \\
\hline Benchmarks & July 2005 & October 2005 & July 2006 \\
\hline ch01 & 31 & 44.8 & 86.9 \\
ch02 & 25.3 & 35.9 & 75.5 \\
ch03 & 21.2 & 29.9 & 61.1 \\
ch04 & 26.5 & 37.9 & 76.8 \\
ch05 & 112.3 & 160.3 & 318.5 \\
ch07 & 20.3 & 29.9 & 61.8 \\
ch08 & 33.5 & 61.7 & 112.2 \\
ch09 & 1.7 & 2.3 & 5.6 \\
ch12 & 0 & 2.4 & 3.6 \\
ch13 & 2.8 & 7.5 & 18.6 \\
ch16 & 73.7 & 126.6 & 233.5 \\
ch20 & 1.1 & 3.1 & 5.8 \\
ch22 & 2.2 & 5 & 6.6 \\
ch23 & -1.5 & -1.5 & -2.1 \\
ch24 & -2.8 & -2.8 & -2.8 \\
ch25 & -2.6 & -2.6 & $105 t$ \\
ch27 & -2.3 & -3.2 & -3.2 \\
ch28 & 0 & 14.8 & 18.5 \\
ch29 & 0 & 8.7 & 11 \\
ch30 & 4.2 & 20.2 & 24.5 \\
Time elapsed since & 8 & 11 & 20 \\
first reading [months] & & & \\
\hline & & & \\
\hline & & & \\
\hline
\end{tabular}

exactly define the velocity of the landslide mapped and to compare these values to those assigned by morphological evidences. Two different hazard maps were thus carried out: the first one takes into account the values of the parameters deduced by the monitoring system and the second mapped just by morphological evidences. The results of this reclassification clearly demonstrate that almost every landslide mapped by morphological evidences in the test site fits with the hazard value calculated from measured data, and only five landslides changed hazard class.

Figures 7 and 8 show an evident resemblance between the hazard classes calculated using the above mentioned methodologies. The landslides mapped on the base of morphological evidences that preserve their hazard class after the correction with the real values average 90 percent.

Moreover the lower class of hazard (H2) is underestimated while the higher hazard class $(\mathrm{H} 4)$ is overestimated, meaning that the new parameters adopted are indeed conservative.

It is possible to assert that with the values adopted in these new matrices the data such as velocity and geometric severity are easy to collect by morphological evidences and properly estimated, making the Swiss approach a reliable methodology in hazard mapping. Finally from the results achieved in this work, it can be assumed that it is possible to extend the effectiveness of this new parameters with good reliability to all the sites in the High Cordevole Valley that have geological and geomorphological characteristics, similar to the Cherz plateau.
Table 4. Rate of planar displacements.

\begin{tabular}{ccccc}
\hline \multicolumn{5}{c}{ Rate of Planar Displacements [cm/month] } \\
\hline $\begin{array}{c}\text { Benchmarks } \\
\text { Jul 05 }\end{array}$ & $\begin{array}{c}\text { Nov 04- } \\
\text { Oct 05 }\end{array}$ & $\begin{array}{c}\text { Jul 05- } \\
\text { Jul 06 }\end{array}$ & Oct 05- & Average \\
\hline ch01 & 3.9 & 4.6 & 4.7 & \\
ch02 & 3.2 & 3.5 & 4.4 & 3.4 \\
ch03 & 2.7 & 2.9 & 3.5 & 3.0 \\
ch04 & 3.3 & 3.8 & 4.3 & 3.8 \\
ch05 & 14.0 & 16.0 & 17.6 & 15.9 \\
ch07 & 2.5 & 3.2 & 3.5 & 3.1 \\
ch08 & 4.2 & 9.4 & 5.6 & 6.4 \\
ch09 & 0.2 & 0.2 & 0.4 & 0.3 \\
ch12 & 0.0 & 0.8 & 0.1 & 0.3 \\
ch13 & 0.3 & 1.6 & 1.2 & 1.0 \\
ch16 & 9.2 & 17.6 & 11.9 & 12.9 \\
ch20 & 0.1 & 0.7 & 0.3 & 0.4 \\
ch22 & 0.3 & 1.0 & 0.2 & 0.5 \\
ch23 & 0.0 & 0.2 & 0.1 & 0.1 \\
ch24 & 0.4 & 0.0 & 0.0 & 0.1 \\
ch25 & 0.3 & 0.0 & & 0.2 \\
ch27 & 0.1 & 0.1 & 0.0 & 0.1 \\
ch28 & 0.0 & 4.9 & 0.4 & 1.8 \\
ch29 & 0.0 & 2.9 & 0.3 & 1.1 \\
ch30 & 0.5 & 5.3 & 0.5 & 2.1 \\
Time elapsed & 11 & 3 & 9 & \\
between surveys & & & & \\
[months & & & & \\
\hline
\end{tabular}

Edited by: T. Glade

Reviewed by: H. Staffler and two other referees

\section{References}

Bosellini, A.: Geologia delle Dolomiti, Athesia Bolzano, 192 pp., 1996.

Canuti, P. and Casagli, N.: Considerazioni sulla valutazione del rischio di frana, Fenomeni franosi e centri abitati eds, CNRGNDCI, 846, 57 pp., 1996.

Castiglioni, G. B.: Note di commento alla carta dell'alluvione del novembre 1966, nel Veneto e nel Trentino Alto Adige: effetti morfologici ed allagamenti, Proc. of XXI Congresso Geografico Italiano, Verbania 1971, Istituto Geografico de Agostini Novara, 2(3), 1973.

Catenacci, V.: Geological and geoenvironmental failure from the post war to 1990, Italy, Roma, Istituto Poligrafico e Zecca dello Stato, 301 pp., 1992.

Crescenti, U.: Il rischio da frana: appunti per la valutazione, Quaderni di Geologia Applicata, 5(2), 87-100, 1998.

Croce, D., Nodari, P., Pellegrini, G. B., Tessari, F.: Effetti dell'alluvione del novembre 1966 sulle sedi abitate delle Tre Venezie. Proc. of XXI Congresso Geografico Italiano, Verbania 1971, Istituto Geografico de Agostini Novara, 2(2), 1973. 


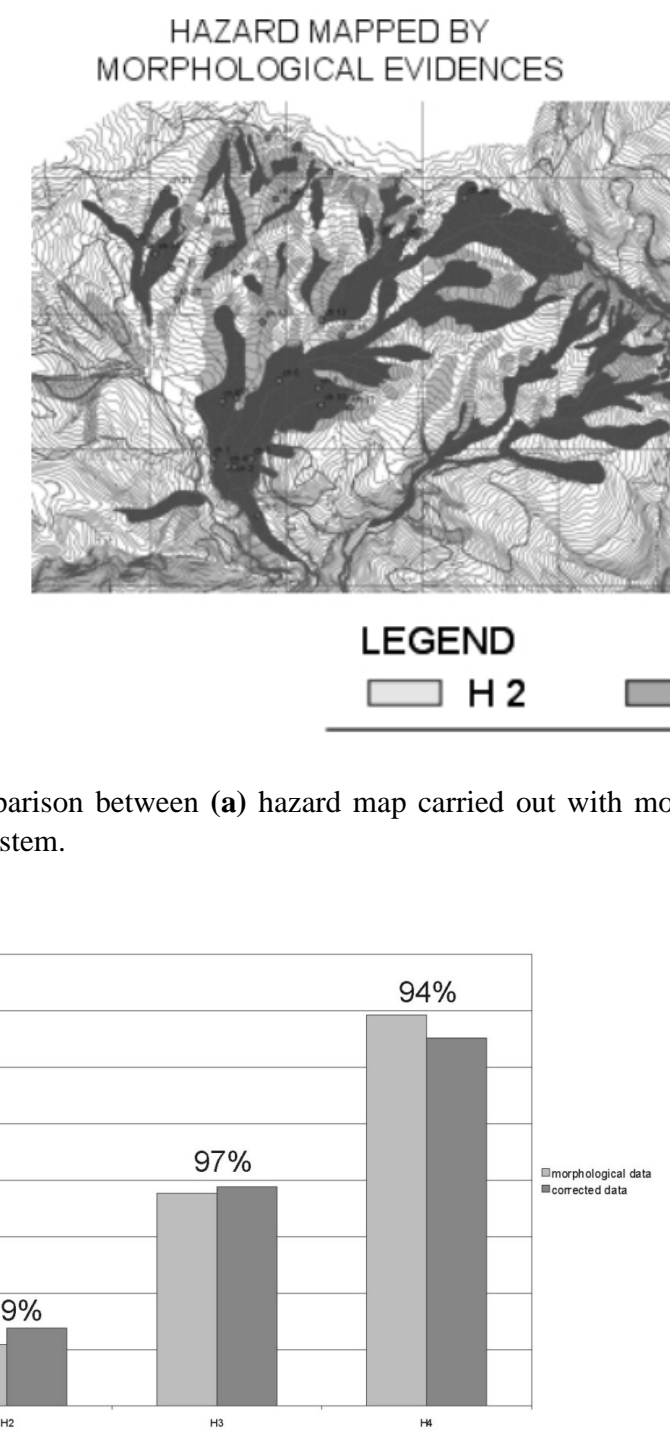

Fig. 8. Diagram of hazard overlapping between the different hazard maps.

Doglioni, C. and Bosellini, A.: Eoalpine and mesoalpine tectonics in the Southern Alps, Geologische Rundschau, 76, 735-754, 1987.

Fell, R.: Landslide risk assessment and acceptable risk, Canadian Geotechnical Journal, 31(2), 261-272, 1994.

Guzzetti, F.: Landslide fatalities and evolution of landslide risk in Italy, Engineering Geology, 58, 89-107, 2000.
Heinimann, H. R., Holtenstein, K., Kienholz, H., Krummenhacher, B., and Mani, P.: Methoden zur Analyse und Bewertung von Naturgefahren, Umwelt-Materialien, Naturgefahren BUWAL, 85, Bern, pp. 248, 1998.

Hofmann-Wellenhof, B., Lichtenegger, H., and Collins, J.: GPS Theory and practice, 5a revised edit., Springer Verlag, Wien, 2001.

Legge 3 agosto 1998, no. 267: Conversione in legge, con modificazioni, del decreto-legge 11 giugno 1998, n. 180, recante misure urgenti per la prevenzione del rischio idrogeologico ed a favore delle zone colpite da disastri franosi nella regione Campania. Gazzetta Ufficiale n. 183 del 7 agosto 1998.

Pasuto, A., Silvano, S., and Tagliavini, F.: Evaluation of landslide hazard and risk in north-eastern Italy, Risk Analysis IV, C. A. Brebbia, pp. 221-233, 2004.

Varnes, D. J.: Landslide Hazard Zonation: a review of principles and practice. Commission on landslide of the IAEG UNESCO, Nat. Hazard, 3, 61 pp., 1984.

Zanchetta, G., Sulpizio, R., Pareschi, M. T., Leoni, F. M., and Santacroce, R.: Characteristics of May 5-6, 1998 volcanoclastic debris flows in the Sarno area (Campania, southern Italy): relationships to structural damage and hazard zonation, Journal of Volcanology and Geothermal Research, 133, 377-393, 2004. 